\title{
Effects of Oxygen on Pyrolysis Kinetics of Tetra Pack
}

\author{
Chao-Hsiung Wu'; Ching-Yuan Chang ${ }^{2}$; Yu-Fen Liư ${ }^{3}$; and Yeou-Lih Yan ${ }^{4}$
}

\begin{abstract}
The effects of oxygen on the pyrolysis of tetra pack, a principal component of municipal solid wastes in Taiwan, were investigated with a thermal gravimetric analysis (TGA) reaction system. The pyrolysis experiments of tetra pack were carried out in four different oxygen concentrations $\left(\mathrm{C}_{\mathrm{O} 2}, 5.37,10.40,14.82\right.$, and 20.95\%) at the heating rates of 5.25, 10.36, and 15.06 K/min. The TGA curves indicated two principal reactions, distinguished by significant and distinct mass changes over the experimental range. Oxygen enhanced the pyrolysis reaction of tetra pack. A kinetic model was proposed for the pyrolysis of the tetra pack in an oxygen environment. The corresponding activation energies, preexponential factors, and reaction orders were determined. The experimental results were satisfactorily fitted by the proposed kinetic model.
\end{abstract}

DOI: 10.1061/(ASCE)0733-9372(2003)129:4(382)

CE Database subject headings: Pyrolysis; Kinetics; Oxygen; Solid wastes.

\section{Introduction}

The major components of tetra pack are kraft paper (about 70\%), low-density polyethylene (PE, about $25 \%$ ), and aluminum foil (about 5\%), generally. There have been many studies on the pyrolysis kinetics of the major components of tetra pack, i.e., kraft paper (cellulose material) and PE. These studies were concerned mostly with the thermal degradation mechanisms of pure cellulose (Bilbao et al. 1987; Gullet and Smith 1987; Calahorra et al. 1989; Soares et al. 1995) and of PE (Albertsson and Karlsson 1988; Darivakis et al. 1990; Chang et al. 1992; Wu and Liang 2001). A number of kinetic models have also been reported to describe the pyrolysis behavior of pure cellulose (Agrawal 1988), of coated/uncoated printing and writing papers (Chang et al. 1996; Wu et al. 1997), and of PE (Shih and Sheu 1983; Wu et al. 1993). Agrawal (1988) proposed a modified Kilzer-Broido model to describe the pyrolysis of cellulose at low temperature $(<573$ $\mathrm{K})$. According to this model, cellulose decomposed via two competitive reactions: A dehydration reaction to form anhydrocellulose and a depolymerization reaction to form levoglucosan. Anhydrocellulose later decomposed to char and gas via two competitive reactions. A simplified two-reaction model was proposed by Chang et al. (1996) and Wu et al. (1997) to illustrate the kinetic behavior of the pyrolysis of uncoated and coated printing and writing paper over $450-900 \mathrm{~K}$ temperature range, respec-

\footnotetext{
${ }^{1}$ Professor, Dept. of Environmental Engineering, Da-Yeh Univ., 112, Shan-Jeau Rd., Dah-Tsuen, Chang-Hwa 515, Taiwan (corresponding author). E-mail: chwu@mail.dyu.edu.tw

${ }^{2}$ Professor, Graduate Institute of Environmental Engineering, National Taiwan Univ., Taipei 106, Taiwan.

${ }^{3}$ Master, Graduate Institute of Environmental Engineering, National Taiwan Univ., Taipei 106, Taiwan.

${ }^{4}$ Associate Professor, Dept. of Environmental Engineering, Da-Yeh Univ., 112, Shan-Jeau Rd., Dah-Tsuen, Chang-Hwa 515, Taiwan.

Note. Associate Editor: Robert G. Arnold. Discussion open until September 1, 2003. Separate discussions must be submitted for individual papers. To extend the closing date by one month, a written request must be filed with the ASCE Managing Editor. The manuscript for this technical note was submitted for review and possible publication on December 12, 2000; approved on April 29, 2002. This technical note is part of the Journal of Environmental Engineering, Vol. 129, No. 4, April 1, 2003. CASCE, ISSN 0733-9372/2003/4-382-386/\$18.00.
}

tively. The corresponding activation energies, preexponential factors, and reaction orders were determined in the experimental conditions. The pyrolysis of PE can be described by the onereaction model and expressed by the overall rate equation with adequate kinetic parameters (Shih and Sheu 1983; Wu et al. 1993). The pyrolysis kinetics of the mixtures of the plastics in municipal solid waste (MSW) were discussed by $\mathrm{Wu}$ et al. (1993). In their study, the pyrolysis experiments of the mixtures of the six principal plastics (low-density PE, high-density PE, polyvinyl chloride, propylene, polystyrene, and acrylonitrilebutadiene-styrene) were performed with a thermal gravimetric analysis (TGA) reaction system. The results indicated that the pyrolysis rate of the mixture could be represented by the weighted sum of the corresponding pyrolysis rates of the components of plastics in MSW.

In the commercial process, the partial oxidation of tetra pack may be controlled adequately to supply the energy needed in the pyrolysis reaction. The results of previous studies do not provide the related data about the effects of oxygen on the pyrolysis kinetics of tetra pack. The aim of the present work was therefore to investigate the effects of oxygen on the pyrolysis of tetra pack in MSW with a view to provide a simple kinetic model for engineering purposes. The pyrolysis of tetra pack was studied with a TGA reaction system at the constant heating rates (HR) of 5.25, 10.36, and $15.06 \mathrm{~K} / \mathrm{min}$. The concentrations of oxygen $\left(\mathrm{C}_{\mathrm{O} 2}\right.$, mole percent of $\mathrm{O}_{2}$ in the mixture of $\mathrm{O}_{2}$ and $\mathrm{N}_{2}$ ) in the carrier gas were $5.37,10.40,14.82$, and $20.95 \%$. The pyrolysis experiments were carried out over a wide temperature range (room temperature$950 \mathrm{~K})$. A kinetic model was then proposed for the pyrolysis of the tetra pack in an oxygen environment.

\section{Experiment}

The print-free tetra pack was used in this study, with the properties as listed in the previous study (Wu and Liu 2001). The nitrogen used to perform these analyses was $99.99 \%$ pure. The experimental system for the pyrolysis of tetra pack is the same as those of the previous study (Wu and Chang 2001). An electrical balance with $0.01 \mathrm{mg}$ precision was used. A sample of known mass (6 $\pm 0.1 \mathrm{mg})$ was placed on a small quartz disk $(2 \mathrm{~cm}$ diameter by 1 


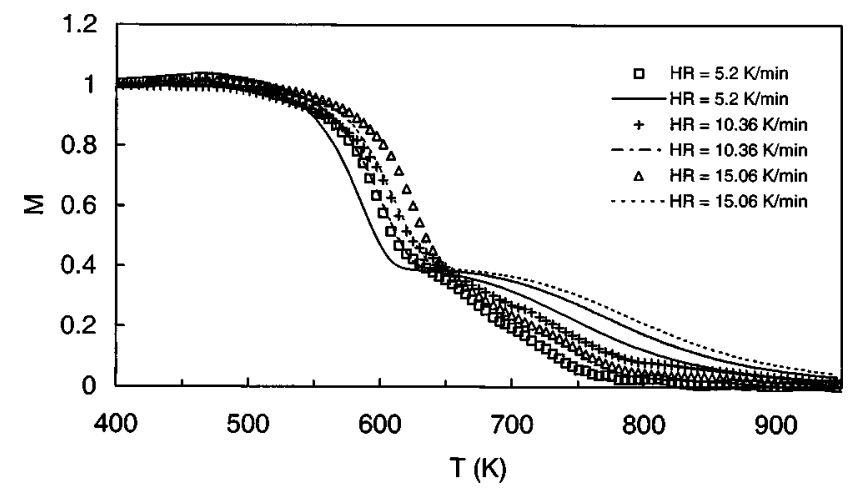

Fig. 1. Comparison of residual mass fraction $(M)$ by model prediction (line), with experimental data (symbol) at different heating rates (HR) for pyrolysis of tetra pack in $\mathrm{C}_{\mathrm{O} 2}=5.37 \%$. $\left(R^{2}=0.97,0.98\right.$, and 0.96 for $\mathrm{HR}=5.25,10.36$, and $15.06 \mathrm{~K} / \mathrm{min}$, respectively.)

mm thick) hung on the suspension wire (platinum, $0.18 \mathrm{~mm} \mathrm{di-}$ ameter) of the balance and enclosed in a quartz shell-and-tube reactor. The outer shell was $67 \mathrm{~cm}$ long with $3.8 \mathrm{~cm}$ inside diameter. The inner tube was $27 \mathrm{~cm}$ long with $1.2 \mathrm{~cm}$ inside diameter. Nitrogen at a high-flow rate was first introduced into the rear channel of the balance cover for $2 \mathrm{~h}$ to purge residual oxygen. The carrier gas of nitrogen with desired $\mathrm{C}_{\mathrm{O} 2}$, which was premixed with needle valves, was introduced into the inner tube of the reactor. The total flow rate of the carrier gas $\left(\mathrm{N}_{2}\right.$ and $\left.\mathrm{O}_{2}\right)$ was $80 \pm 2 \mathrm{~cm}^{3} / \mathrm{min}$ (at $101.3 \mathrm{kPa}$ and $293 \mathrm{~K}$ ). After about $0.5 \mathrm{~h}$ the reactor was placed in the furnace $(1.28 \mathrm{~kW})$, which had been preset to a specified heating rate $(5.25,10.36$, or $15.06 \mathrm{~K} / \mathrm{min})$. When the control units were all ready, the pyrolysis run was begun. The reaction temperature and mass of sample were recorded at time intervals of $10 \mathrm{~s}$ by the computerized dataprocessing unit. The pyrolysis process was operated under atmospheric pressure. The effluent stream leaving the outer shell was passed through a water trap before venting to a fume hood. When the pyrolysis was ended, the furnace was turned off. The carrier gas of $\mathrm{N}_{2}$ was kept flowing until the temperature of reactor was cooled below $373 \mathrm{~K}$.

\section{Results and Discussion}

\section{Pyrolysis of Tetra Pack}

The final residues masses $\left(W_{f}\right)$ of tetra pack at different oxygen concentrations and heating rates are about $10-16 \%$ of the initial sample masses. The residue with a mass of $W$ after pyrolysis was expressed on a normalized basis as residual mass fraction $M$ $=\left(W-W_{f}\right) /\left(W_{0}-W_{f}\right), W_{0}$ is the initial sample mass. The variations of $M$ with reaction temperature $(T)$ at $\mathrm{C}_{\mathrm{O} 2}=5.37 \%$, for example, is shown in Fig. 1. The variations of $M$ with $T$ for $\mathrm{C}_{\mathrm{O} 2}$ $=10.40,14.82$, and $20.95 \%$ are similar to that of $\mathrm{C}_{\mathrm{O} 2}=5.37 \%$. Obviously, there were two principal reactions as distinguished by the two significant and distinct mass changes over the temperature range 400-950 $\mathrm{K}$ for all the TGA curves. When the temperature reached about $450-500 \mathrm{~K}$, the first distinct mass change began and proceeded until $M$ was 0.4 and then slowly. The second distinct mass change began at a residual mass fraction of about 0.38 and proceeded slowly to the end. At a lower-heating rate, the time required for the polymer to reach a given temperature was longer. This would generally result in a higher conversion. Hence, the

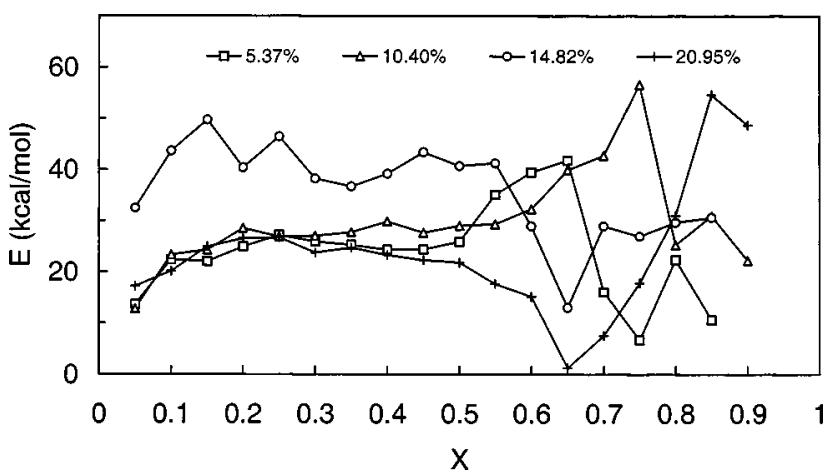

Fig. 2. Activation energies $(E)$ at different conversions $(X)$ for pyrolysis of tetra pack in $\mathrm{C}_{\mathrm{O} 2}=5.37,10.40,14.82$, and $20.95 \%$

residual mass curve at a lower-heating rate is below or to the left of that at a higher-heating rate. For the same heating rate, the curves of the residual mass fraction were influenced while moving to the lower-temperature region at a higher oxygen concentration (Wu and Liu 2001). This indicated that oxygen affects the pyrolysis products as well as the pyrolysis kinetics.

Some common methods used for dealing with the pyrolysis data have been developed and employed by previous investigators (Petrovic and Zavargo 1986; Wu et al. 1993). These methods were primarily based on the following equation:

$$
r=d X / d t=k(1-X)^{n}
$$

where $r=$ instantaneous reaction rate; $X=$ conversion at time $t$; $n=$ reaction order taking account of the pyrolysis of solid waste; and $k=$ reaction rate constant depending on the pyrolysis temperature according to the Arrhenius relation $[k=A \exp (-E / R T)]$. Because oxygen participated the pyrolysis reaction, the concentration term of oxygen must be combined in the rate equation. That is

$$
r=d X / d t=k(1-X)^{n}\left(\mathrm{O}_{2}\right)^{m}
$$

where $\left(\mathrm{O}_{2}\right)=$ concentration of oxygen in mole fraction and $m$ $=$ reaction order taking account of the effects of oxygen on the pyrolysis reaction.

The differential method for determining the activation energy $(E)$ was employed in this study. Taking the natural logarithm of Eq. (2) yielded $\ln (d X / d t)=\ln \left[A(1-X)^{n}\right]+m \ln \left(\mathrm{O}_{2}\right)-E / R T$. At the same degree of conversion and constant oxygen concentration, the reaction temperatures were different under the various heating rates. A desired residual mass fraction (or conversion) was specified from Fig. 1. Then, the reaction temperatures corresponding to the various heating rates were obtained. Simultaneously, a set of instantaneous rates $(d X / d t)$ was deduced corresponding to these reaction temperatures from the instantaneous reaction rate curves. A straight line with slope $(-E / R)$ was obtained by plotting $\ln (d X / d t)$ versus $1 / T$. The value of $E$ corresponding with the selected conversion and oxygen concentration would then be obtained. The activation energies under different conversions and oxygen concentrations are shown in Fig. 2. The results indicated that the activation energies of the pyrolysis of tetra pack were in the range of about $2-57 \mathrm{kcal} / \mathrm{mol}$. These values may be divided into two groups $(X \leqq 0.6$ and $X>0.6)$ for every oxygen concentration. It is noted that the activation energy from the one with an $\mathrm{O}_{2}$ concentration of $14.8 \%$ is much higher than that of other ones with different $\mathrm{O}_{2}$ concentrations. The same result was obtained for another run of the pyrolysis with an $\mathrm{O}_{2}$ concentration of $14.8 \%$. To check the irregular distribution in activation energy, 


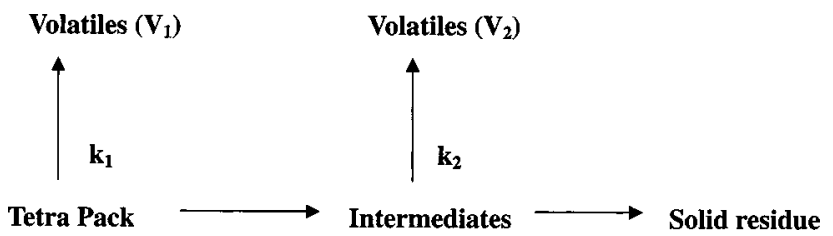

Fig. 3. Reaction scheme of tetra pack pyrolysis in oxygen environment. ( $k_{1}, k_{2}$ : reaction rate constants)

further pyrolysis runs under different $\mathrm{O}_{2}$ concentrations (say, $\mathrm{C}_{\mathrm{O} 2}=12,14,16$, and $18 \%$ ) may be helpful.

\section{Kinetic Model}

Examining the results of this study, the trend of the TGA curves was similar to that of tetra pack pyrolysis in a nitrogen environment (Wu and Chang 2001). The first pyrolysis reaction of tetra pack in the oxygen environment was in the temperature range below about $650 \mathrm{~K}(X \leqq 0.6)$. It was contributed mainly by the first reaction of kraft paper. The residual mass fraction of the pyrolysed sample decreased from 1.0 to about 0.4 for all the TGA curves. The degradation reactions of cellulose and hemicellulose in kraft paper were considered as an overall reaction. The products of this reaction were intermediates and volatiles. The second reaction was in the temperature range of about 650 to $950 \mathrm{~K}$ ( $X$ $>0.6$ ). It was contributed mainly by the second reaction of kraft paper and the degradation of low-density PE. Since the pyrolysis reactions included the degradation of low-density PE and the decomposition of various intermediates to form volatiles and solid residue. The activation energy fluctuated violently at this stage. However, the pyrolysis reactions were also considered as a representative reaction for engineering purpose. The product distributions have been determined in the previous study ( $\mathrm{Wu}$ and Liu 2001).

From the TGA curves in this study and the product distribution of tetra pack pyrolysis in an oxygen environment ( $\mathrm{Wu}$ and Liu 2001), a two-reaction model (as shown in Fig. 3) is therefore proposed. Based on the proposed model and the Arrhenius law, the residual mass fraction $M$ may be obtained by the following equations:

$$
\begin{gathered}
M=\left(W-W_{f}\right) /\left(W_{0}-W_{f}\right)=1-m_{V_{1}}-m_{V_{2}} \\
X_{1}=m_{v 1} / F_{1} \\
X_{2}=m_{v 2} / F_{2} \\
d\left(m_{V_{1}} / F_{1}\right) / d t=k_{1}\left[1-\left(m_{v 1} / F_{1}\right)\right]^{n 1}\left(\mathrm{O}_{2}\right)^{m 1} \\
d\left(m_{v 2} / F_{2}\right) / d t=k_{2}\left[1-\left(m_{v 2} / F_{2}\right)\right]^{n 2}\left(\mathrm{O}_{2}\right)^{m 2}
\end{gathered}
$$

where $k_{1}=A_{1} \exp \left(-E_{1} / R T\right)$ and $n_{1}$, and $k_{2}=A_{2} \exp \left(-E_{2} / R T\right)$ and $n_{2}=$ reaction rate constants and reaction orders of reactions 1 and 2 , respectively; and $m_{v 1}=W_{v 1} /\left(W_{0}-W_{f}\right)$ and $m_{v 2}$ $=W_{v 2} /\left(W_{0}-W_{f}\right)=$ mass fractions of volatiles $V_{1}$ and $V_{2}$, respectively. Eqs. (3) -(7) satisfy the following conditions:

$$
M=1, \quad m_{v 1}=m_{v 2}=0 \text { at } t=0
$$

In Eqs. (4)-(7), $F_{1}$ and $F_{2}$ are the weighting factors taking account of the decrease in the residual mass fraction contributed by pyrolysis reactions $1(<650 \mathrm{~K})$ and $2(650-950 \mathrm{~K})$, respectively. From the TGA curves, $F_{1}$ and $F_{2}$ are estimated to be about 0.6 and 0.4 , respectively.
When $n_{1}, n_{2} \neq 1$, Eqs. (6) and (7) were solved to give the following solutions:

$$
\begin{aligned}
m_{v 1} / F_{1} \cong & 1-\left\{1-A_{1} R T^{2}\left(1-n_{1}\right)\left(\mathrm{O}_{2}\right)^{m 1} \exp \left(-E_{1} / R T\right)\right. \\
& \times\left[1-2 /\left(E_{1} / R T\right)+6 /\left(E_{1} / R T\right)^{2}\right. \\
& \left.\left.-24 /\left(E_{1} / R T\right)^{3}+\cdots\right] / E_{1} H R\right\}^{1 /(1-n 1)} \\
m_{v 2} / F_{2} \cong & 1-\left\{1-A_{2} R T^{2}\left(1-n_{2}\right)\left(\mathrm{O}_{2}\right)^{m 2} \exp \left(-E_{2} / R T\right)\right. \\
& \times\left[1-2 /\left(E_{2} / R T\right)+6 /\left(E_{2} R T\right)^{2}\right. \\
& \left.\left.-24 /\left(E_{2} / R T\right)^{3}+\cdots\right] / E_{2} H R\right\}^{1 /(1-n 2)}
\end{aligned}
$$

where $\mathrm{HR}=d T / d t$ heating rate; $A_{1}$ and $E_{1}$ and $A_{2}$ and $E_{2}$ $=$ preexponential factors of Arrhenius-terms and the activation energies of Pyrolysis Reactions 1 and 2, respectively; $T$ = pyrolysis temperature; and $m_{1}$ and $m_{2}=$ reaction order taking account of the effects of oxygen on the Pyrolysis Reactions 1 and 2 , respectively.

The principal components of tetra pack are kraft paper LDPE and aluminum foil. The kraft paper also consists mostly of cellulose together with a small fraction of hemicellulose, additives, and impurities, etc. Owing to the variety of components in tetra pack, its pyrolysis behavior may differ significantly from that of pure component. In addition, the molecular structure of the residue may vary during pyrolysis and differ from the original one, which was observed in the distribution of activation energy. For engineering purposes, it was necessary to select a set of representative kinetic parameters in applying Eqs. (3), (9), and (10). The activation energies for Pyrolysis Reactions 1 and 2 were obtained by taking arithmetic averages over the conversion ranges $X$ $=0.1-0.6$ and $X=0.6-0.85$, respectively. This gave $E_{1}=27.02$, $27.83,40.82$, and $22.47 \mathrm{kcal} / \mathrm{mol}$ for $\mathrm{C}_{\mathrm{O} 2}=5.37,10.40,14.82$, and $20.94 \%$, and $E_{2}=19.54,39.11,25.86$, and $22.47 \mathrm{kcal} / \mathrm{mol}$ for $\mathrm{C}_{\mathrm{O} 2}=5.37,10.40,14.82$, and $20.94 \%$, respectively. Based on the reaction kinetics, the activation energy is constant for the Pyrolysis Reactions 1 or 2 even at different oxygen concentrations. The activation energies for Pyrolysis Reactions 1 and 2 were obtained by taking arithmetic averages over four different oxygen concentrations. This gave $E_{1}=29.53$ and $E_{2}=26.74 \mathrm{kcal} / \mathrm{mol}$.

Rearranging Eq. (2) and taking natural logarithms gives

$$
\ln [(d X / d t) / \exp (-E / R T)]=n \ln (1-X)+\ln A+m \ln \left(\mathrm{O}_{2}\right)
$$

With the substitution of the instantaneous rates and the activation energy (29.53 or $26.74 \mathrm{kcal} / \mathrm{mol})$ into Eq. (11), a straight line with slope $n$ and intercept $\ln A+m \ln \left(\mathrm{O}_{2}\right)$ was obtained by plotting $\ln [(d X / d t) / \exp (-E / R T)]$ against $\ln (1-X)$ at constant oxygen concentration. This gave $n_{1}=0.93,0.73,0.75$, and 0.78 for $\mathrm{C}_{\mathrm{O} 2}$ $=5.37,10.40,14.82$, and 20.94\%, and $n_{2}=2.72,2.00,2.38$, and 2.16 for $\mathrm{C}_{\mathrm{O} 2}=5.37,10.40,14.82$, and $20.94 \%$, respectively. The reaction order is also constant for the Pyrolysis Reactions 1 or 2 even at different oxygen concentrations. The reaction orders for Pyrolysis Reactions 1 and 2 were obtained by taking arithmetic averages over four different oxygen concentrations. This gave $n_{1}=0.80$ and $n_{2}=2.32$.

Also, rearranging Eq. (2) and taking natural logarithms gives

$$
\begin{aligned}
\ln \left[(d X / d t) /(1-X)^{n}\right] & =(-E / R T)+\ln A+m \ln \left(\mathrm{O}_{2}\right) \\
& =\ln k+m \ln \left(\mathrm{O}_{2}\right)
\end{aligned}
$$

The activation energy can be further revised using Eq. (12). For the constant oxygen concentration, with the substitution of reaction orders $n_{1}=0.80$ or $n_{2}=2.32$ into Eq. (12), a straight line 
with slope $(-E / R)$ and intercept $\ln A+m \ln \left(\mathrm{O}_{2}\right)$ was obtained by plotting $\ln \left[(d X / d t) /(1-X)^{n}\right]$ against $1 / T$. The value of $E$ for Pyrolysis Reactions 1 or 2 corresponding with the selected oxygen concentration would then be obtained. The activation energies for Pyrolysis Reactions 1 and 2 were obtained by taking arithmetic averages over four different oxygen concentrations. This gave the revised activation energies $E_{1}=26.55$ and $E_{2}=23.39 \mathrm{kcal} / \mathrm{mol}$. Also, the preexponential factor is constant for the Pyrolysis Reactions 1 or 2 even at different oxygen concentrations. By the linear regression, a straight line with slope $m$ and intercept $\ln A$ was obtained by plotting $\ln A+m \ln \left(\mathrm{O}_{2}\right)$ against $\ln \left(\mathrm{O}_{2}\right)$. Thus, the preexponential factors and reaction orders in oxygen concentration term were $A_{1}=7.03 \times 10^{6} \mathrm{~s}^{-1}$ and $m_{1}=-0.48, A_{2}=9.29$ $\times 10^{5} \mathrm{~s}^{-1}$ and $m_{2}=1.47$ for the Pyrolysis Reactions 1 and 2, respectively.

The computed values for the model simulation of residual mass fraction with the parameter values $\left(A_{1}, A_{2}=7.03 \times 10^{6}\right.$, $9.29 \times 10^{5} \mathrm{~s}^{-1}, E_{1}, E_{2}=26.55,23.39 \mathrm{kcal} / \mathrm{mol}, F_{1}, F_{2}=0.6,0.4$, $m_{1}, m_{2}=-0.48,1.47$, and $\left.n_{1}, n_{2}=0.80,2.32\right)$ were compared with the experimental data shown in Fig. 1. The coefficients of determination $\left(R^{2}\right)$, computed at the range of 5-95\% of the final loss $\left(W_{0}-W_{f}\right)$, are close to 1 for $\mathrm{C}_{\mathrm{O} 2}=5.37,10.40,14.82$, and $20.94 \%$. The computed results for the proposed model gave good agreement with the experimental data under the examined conditions. This thus supported the validity and practical applicability of the proposed kinetic model in the oxygen concentration range of 5.37 to $20.95 \%$.

\section{Conclusions}

Pyrolysis experiments of tetra pack were carried out in a TGA reaction system at the heating rates of 5.25, 10.36, and 15.06 $\mathrm{K} / \mathrm{min}$. The effects of oxygen on the pyrolysis reaction were investigated over the oxygen concentrations range of 5.37-20.95\%. A simplified two-reaction model was proposed to illustrate the kinetic behavior of the pyrolysis of tetra pack in an oxygen environment. The corresponding activation energies, preexponential factors and reaction orders were determined in the experimental conditions. Oxygen enhanced the pyrolysis reaction of tetra pack. The final residual masses were about $10-16 \%$ of the initial sample masses. The values were close to the ash content of tetra pack. This thus indicated that the combustibles of tetra pack could be effectively converted into fuels or primary chemicals by the pyrolysis method. The kinetic data obtained in this study would provide useful information for the pyrolytical treatment of the waste tetra pack in MSW.

\section{Acknowledgments}

The writers express their sincere thanks to the National Science Council of Taiwan for its financial support under Project No. NSC 88-2211-E-212-002.

\section{Notation}

The following symbols are used in this paper:

$A=$ preexponential factor of Arrhenius term (1/s);

$A_{1}, A_{2}=A$ of pyrolysis reactions $1,2(1 / \mathrm{s})$;

$\mathrm{C}_{\mathrm{O} 2}=$ oxygen concentration in mole percent $(\%)$;

$E=$ activation energy $(\mathrm{kcal} / \mathrm{mol})$;

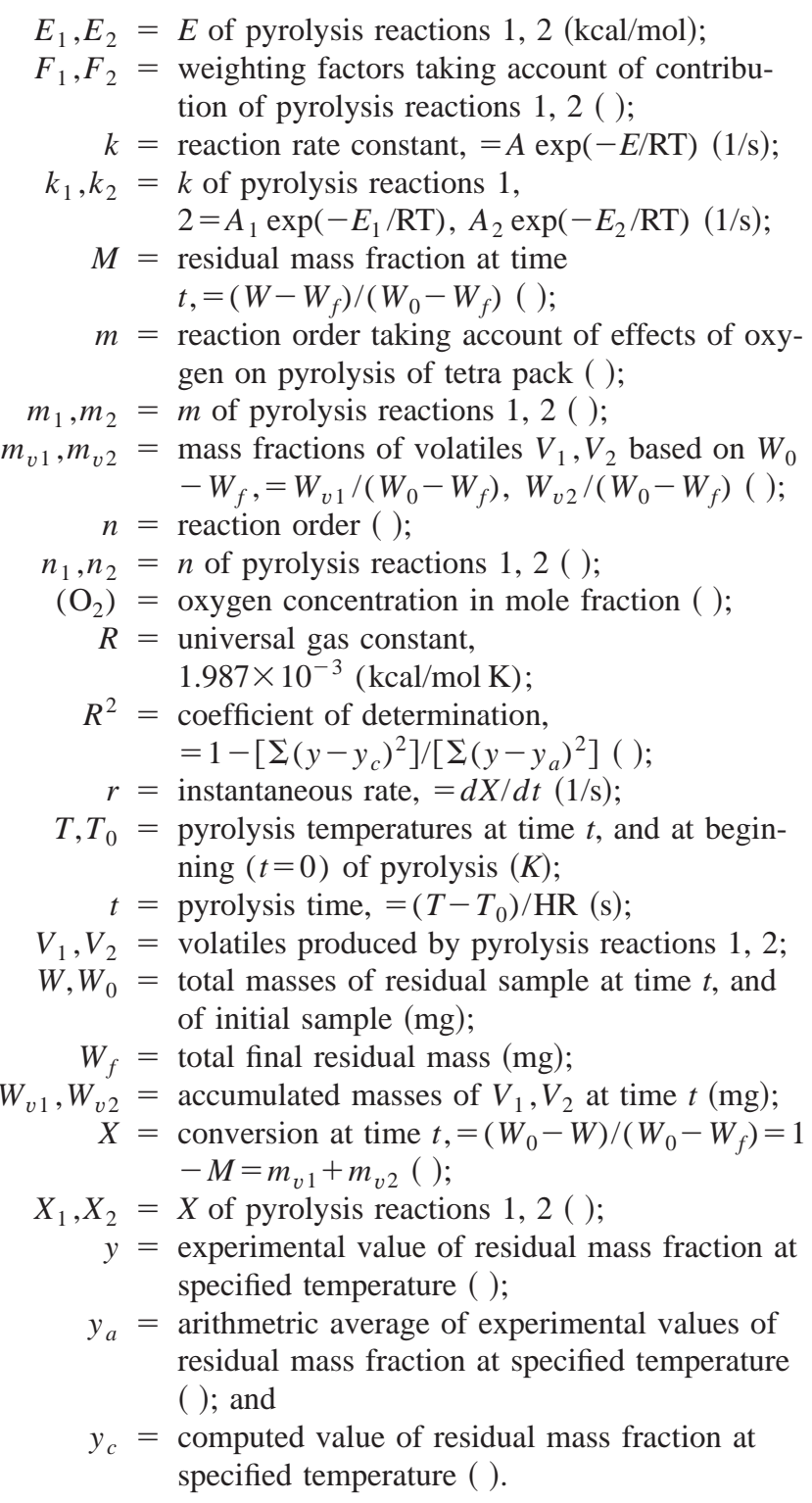

\section{References}

Agrawal, R. K. (1988). "Kinetics of reactions involved in pyrolysis of cellulose. II: The modified Kilzer-Broido model." Can. J. Chem. Eng., 66, 413-418.

Albertsson, A. C., and Karlsson, S. (1988). "The three stages in degradation of polymers-polyethylene as a model substance." J. Appl. Polym. Sci., 35, 1289-1302.

Bilbao, R., Arauzo, J., and Millera, A. (1987). "Kinetics of thermal decomposition of cellulose. Part I. Influence of experimental conditions." Thermochim. Acta, 120, 121-131.

Calahorra, M. E., Cortazar, M., Eguiazabal, J. I., and Guzman, G. M. (1989). "Thermogravimetric analysis of cellulose: Effect of the molecular weight on the decomposition." J. Appl. Polym. Sci., 37, 33053314.

Chang, C. Y., Wu, C. H., Hor, J. L., Shih, S. M., and Chen, L. W. (1992). "Pyrolysis kinetics of polyethylene." J. Chin. Inst. Environ. Eng., 2(2), 125-133.

Chang, C. Y., Wu, C. H., Hwang, J. Y., Lin, J. P., Yang, W. F., Shih, S. M., Chen, L. W., and Chang, F. W. (1996). "Pyrolysis kinetics of uncoated printing and writing paper of MSW." J. Environ. Eng., 122(4), 299305.

Darivakis, G. S., Howard, J. B., and Peters, W. A. (1990). "Release rates of condensables and total volatiles from rapid devolatilization of poly- 
ethylene and polystyrene." Combust. Sci. Technol., 74, 267-281.

Gullett, B. K., and Smith, P. (1987). "Thermogravimetric study of the decomposition of pelletized cellulose at $315^{\circ} \mathrm{C}-800^{\circ} \mathrm{C}$." Combust. Flame, 67, 143-151.

Petrovic, Z. S., and Zavargo, Z. Z. (1986). "Reliability of methods for degradation of kinetic parameters from thermogravimetry and DSC measurements." J. Appl. Polym. Sci., 32, 4353-4367.

Shih, S. M., and Sheu, J. C. (1983). "Kinetics of high-density polyethylene pyrolysis in nitrogen." J. Chin. Inst. Chem. Eng., 14, 485-490.

Soares, S., Camino, G., and Levchik, S. (1995). "Comparative study of the thermal decomposition of pure cellulose and pulp paper." Polym. Degrad. Stab., 49, 275-283.
Wu, C. H., and Chang, H. S. (2001). "Pyrolysis of tetra pack in municipal solid waste." J. Chem. Technol. Biotechnol., 76(8), 779-792.

Wu, C. H., and Liang, Y. (2001). "Thermal treatment of polyethylene in system containing hydrogen chloride.” J. Environ. Eng., 127(1), 7076.

Wu, C. H., and Liu, Y. F. (2001). "Pyrolysis products of tetra pack in different oxygen concentrations." Energy Fuels, 15(4), 841-847.

Wu, C. H., Chang, C. Y., Hor, J. L., Shih, S. M., Chen, L. W., and Chang, F. W. (1993). "On the thermal treatment of plastic mixtures of MSW: Pyrolysis kinetics." Waste Manage. Res., 13, 221-235.

Wu, C. H., Chang, C. Y., Lin, J. P., and Hwang, J. Y. (1997). “Thermal treatment of coated printing and writing paper in MSW: Pyrolysis kinetics." Fuel, 76, 1151-1157. 